

Universidad

Euskal Herriko del País Vasco

Unibertsitatea



\section{Phagocytic activity of haemocytes from Galleria mellonella larvae infected with Candida glabrata, Candida nivariensis and}

\section{Candida bracarensis}

Ainara Hernando, Estibaliz Mateo, Elena Eraso and Guillermo Quindós

Departamento de Inmunología, Microbiología y Parasitología

Facultad de Medicina y Enfermería, Universidad del País Vasco/Euskal Herriko Unibertsitatea (UPV/EHU), Bilbao, Spain

(GIC15/78 IT-990-16, UFI 11/25). ainara.hernando@ehu.eus

\begin{abstract}
Introduction
Candida glabrata is the second or third leading cause of invasive candidiasis in many European countries. This species has acquired a relevant clinical significance because of its low sensitivity to current azole antifungal drugs. Candida glabrata has two related species, Candida nivariensis and Candida bracarensis. The innate immune system of Galleria mellonella has similarities with the innate immune system of vertebrates. Therefore, it is interesting to study the ability of hemocytes to phagocytose pathogens.
\end{abstract}

\title{
Objectives
}

To assess the phagocytic capacity of haemocytes from Galleria mellonella larvae infected with Candida glabrata, Candida nivariensis and Candida bracarensis.

\section{Methods}

Galleria mellonella larvae were distributed in groups of five and infected with $10 \mu \mathrm{l}$ of $1 \times 10^{6}$ cells $/ \mathrm{ml}$ of each of the following reference strains: Candida glabrata ATCC 90030, Candida glabrata NCPF 3203 Candida nivariensis CBS 9984, Candida nivariensis CECT 11998, Candida bracarensis NCYC 3397 and

Yeast cells were previously stained with Calcofluor White for $30 \mathrm{~min}$ at $37^{\circ} \mathrm{C}$ and washed twice in PBS buffer.

Larvae were injected with Candida in the last left pro-leg using a precision syringe and incubated for $2 \mathrm{~h}$ at $37^{\circ} \mathrm{C}$.
Haemolymph of each larva was collected and $50 \mu \mathrm{l}$ were diluted in the same volume of IPS buffer (insect physiological saline) to avoid melanisation Phagocytosis quantification was performed counting the percentage of haemocytes with cells phagocytised and without cells phagocytised. Candida bracarensis NCYC 3133.

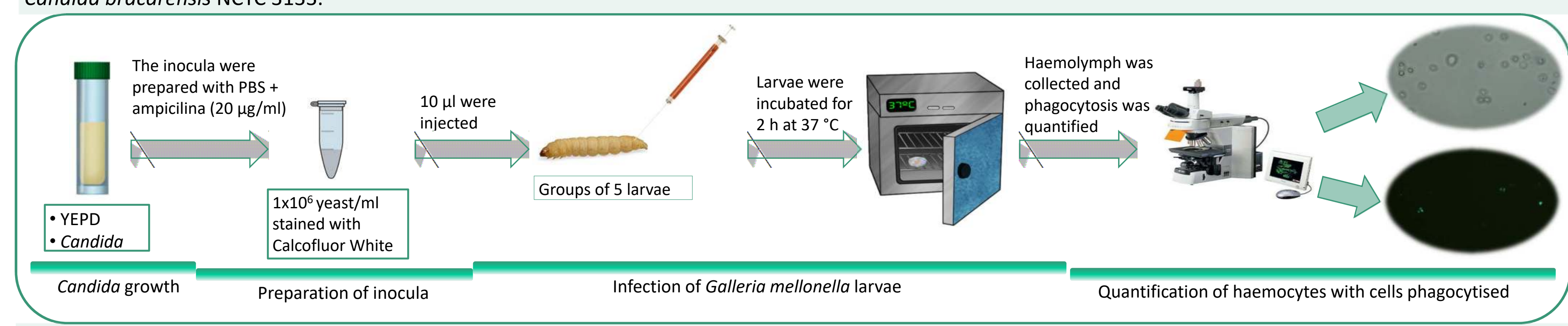

Experiments were performed at least three times on different days and, at least, 100 haemocytes were counted.

The results obtained were analysed using one-way ANOVA to evaluate the differences between strains $(p<0.05$ was considered as statistically significant).

\section{Results}

- Larvae infected with both Candida glabrata strains presented the same phagocytosis capacity $(8.02$ and $7.91 \%)$ and no statistically significant differences in the phagocytosis percentage between them were observed (Figure 1 and Table 1 ).

- Larvae infected with both Candida bracarensis strains (10.2 and 8.33\%) presented slight differences between them, but no significant differences were observed. The phagocytosis obtained with Candida bracarensis NCYC $3397(10.2 \%)$, the highest result obtained in this work, showed differences with those observed in larvae infected with Candida glabrata and Candida nivariensis (Figure 1 and Table 1).

- Larvae infected with both Candida nivariensis strains presented statistically significant differences in the phagocytosis percentage between them(7.82 and $4.32 \%)$. The result obtained after infection with Candida nivariensis CECT 11998 (4.32\%) was the lowest phagocytosis percentage obtained in this work, and presented differences respect to all analysed Candida strains (Figure 1 and Table 1).

Table 1: Differences in the phagocytic activities of haemocytes from larvae infected with $1 \times 10^{6} \mathrm{cells} / \mathrm{ml}$ of

Candida glabrata, Candida nivariensis and Candida bracarensis.

\begin{tabular}{|lc|}
\hline \multicolumn{1}{|c|}{ Candida strains } & Phagocytosis (\%) \\
\hline Candida glabrata ATCC $\mathbf{9 0 0 3 0}$ & $8.02^{* / \#}$ \\
\hline Candida glabrata NCPF $\mathbf{3 2 0 3}$ & $7.91^{* / \#}$ \\
\hline Candida nivariensis CBS $\mathbf{9 9 8 4}$ & $7.82^{* / \#}$ \\
\hline Candida bracarensis CECT $\mathbf{1 1 9 9 8}$ & $4.32^{*}$ \\
\hline Candida bracarensis NCYC $\mathbf{3 1 3 3}$ & $10.20^{*}$ \\
\hline
\end{tabular}

Candida bracarensis NCYC 3133

* statisically significant differences with Candida nivariensis CECT 11998

\# statistically significant differences detected with Candida bracarensis NCYC 3397

\section{Conclusion}

The phagocytic activity of haemocytes from infected Galleria mellonella larvae is a useful tool to study invasive candidiasis caused by Candida glabrata, Candida nivariensis and Candida bracarensis. The phagocytosis activities observed in Galleria mellonella larvae infected with Candida were similar for all strains tested except for Candida bracarensis NCYC 3397 and for Candida nivariensis CECT 11998.

\section{Funding}

This study was partially financed by GIC15/78 IT-990-16 (Gobierno Vasco-Eusko Jaurlaritza). AH has a grant from the UPV/EHU. 